\title{
How the economics profession got it wrong on Brexit
}
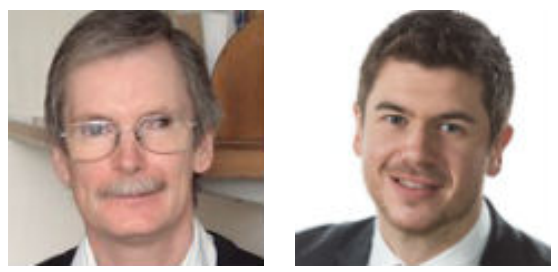

\begin{abstract}
Some of the most widely cited predictions of the economic effects of Brexit rely on flawed analysis, particularly of the performance of the UK after it joined the $E E C$, and on the link between trade and productivity, write Ken Coutts (left), Graham Gudgin (University of Cambridge) and Jordan Buchanan (right) (UIster University Economic Policy Centre). In order to restore public confidence in economic forecasting for major policy issues, economists need to use more relevant analyses, based on a wider range of evidence.
\end{abstract}

The Brexit debate has been distorted by several myths. One of the most persistent and widely repeated is that the economic performance of the UK improved after joining the EEC in 1973. This claim was made by the OECD and was regularly stated in the media during the Brexit referendum campaign. The link between trade and productivity also plays an important role in economists' assessments of the economic performance of the UK within the EU, and the short-term and long-term economic effects of the referendum decision to leave the EU.

Many of these assessments have been by government departments and international agencies. In estimating the economic effects of Brexit on living standards, these rely on a range of analytic approaches, including the use of gravity models, computable general equilibrium models and macroeconomic forecasting models.

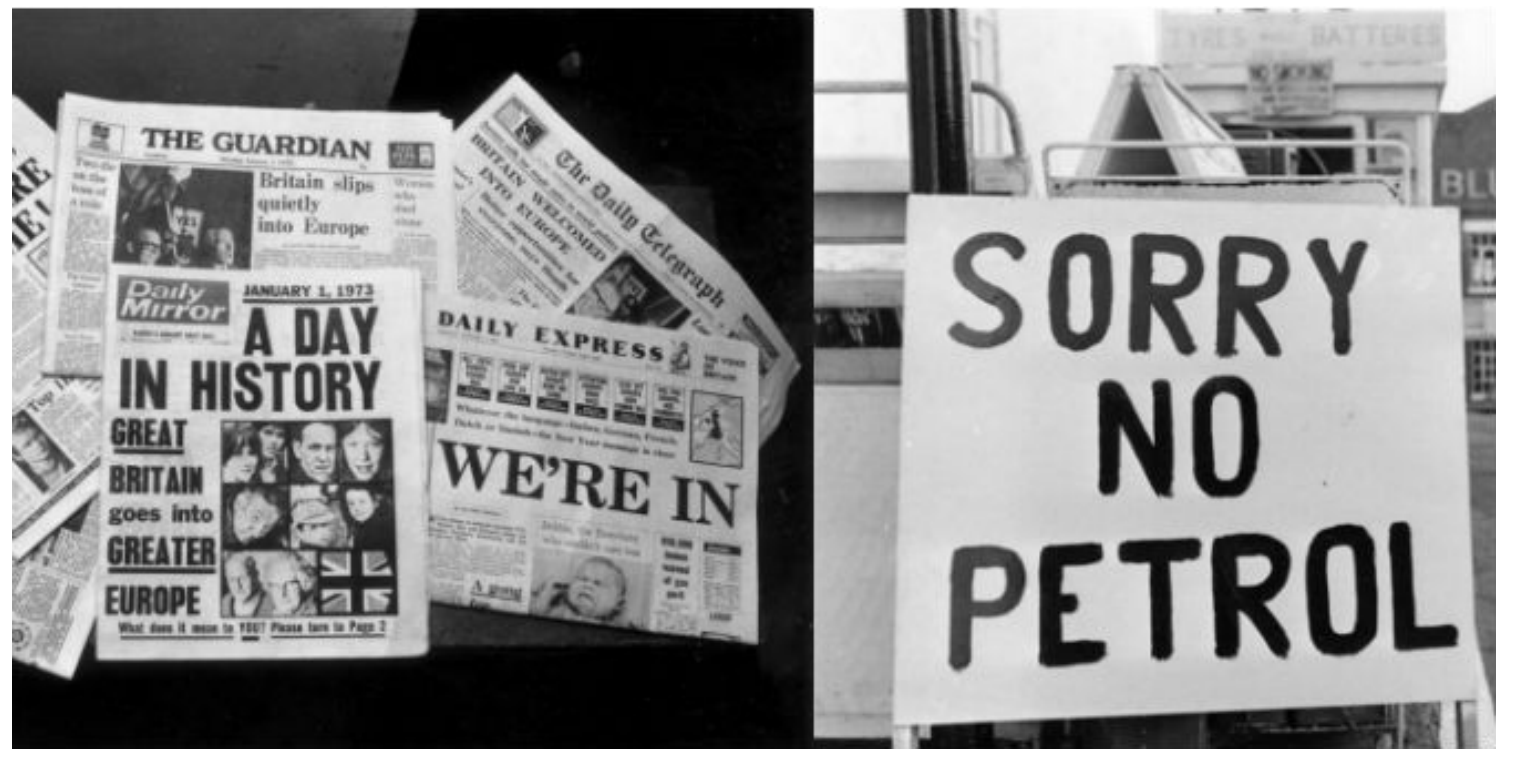

Front pages celebrate the UK's entry into the EEC in 1973, a time of fuel shortages. Photo: Paul Townsend via a CC-BY-SA 2.0 licence

In our working paper, we conclude that much of this work contains flaws of analysis, and a treatment of evidence that leads to exaggerated costs of Brexit. Gravity models are well established as a technique for estimating the impact of trade associations or currency unions but require more care than has been in shown, when being applied to a specific issue like Brexit. The Treasury has been particularly cavalier in its approach, both in its application of gravity analysis and in applying a 'knock-on' impact from trade to productivity. Other organisations have been a little more circumspect about the productivity link, which we doubt exists to any significant degree for advanced economies, but several have used it without much questioning. The short-term forecasts which have turned out to be wrong have further damaged confidence in economists' contributions to public debate.

Partly as a result, very little attention is currently being given by politicians or the public on either side of the debate to the impact assessments published at the time of the referendum. The potential damage to the UK's negotiating position on Brexit may have been limited by the indifference of policy-makers to economic impact assessments. Although the UK government has steered away from further work on economic assessments of Brexit, devolved governments have felt less constrained. 
The Mayor of London, reacting against the UK Government's reluctance to publish assessments, commissioned Cambridge Econometrics, who showed that a modelling approach without gravity models or general equilibrium, will generate moderate and plausible results. Even so, only the most pessimistic of their conclusions on Brexit received any publicity. CE's gave little attention to their prediction that per capita GVA was little changed by Brexit and hence the media ignored it.

The Scottish Government was much less inhibited and ploughed ahead with an analysis incorporating all of the flaws in the Treasury and CEP analyses with no acknowledgement of published criticisms. The consequences of these shortcomings go well beyond Brexit itself.

We believe that the credibility of the economic forecasting profession and some of the major parts of the economic press, have been damaged again. It will take more than a decade to be sure of this, but the failure of the short-term forecasts indicates what could happen. The fact that the flaws we identify all point in the direction of pessimism on Brexit, and hence in the direction that most academics and economists tend to lean ideologically, will increase the scepticism of many. The refusal of the Treasury to discuss their approach, at least until the issue was aired in Parliament, is in our view unacceptable in an open democracy.

Our conclusion is that in order to restore public confidence in economic forecasting for major policy issues like Brexit, economists need to use more relevant analyses, based on a wider range of evidence. We expect that econometric models used by commercial forecasters like Cambridge Econometrics, will prove to be most accurate in the long-run. If so, the academic profession needs to reconsider both the relevance of its current attachment to theory based on unrealistic assumptions, and to the general quality of policy-relevant applied work.

Whatever techniques are used need to be applied with more balance and scepticism. The CEP in discussing the Treasury reports could only think of changes which would have made the HMT predictions even more pessimistic on Brexit. In the words of Oliver Cromwell to the General Assembly of the Church of Scotland, the economic forecasting profession needs to 'think it possible ye may be mistaken'.

Our conclusion is that most estimates of the impact of Brexit in the UK, both short-term and long-term, have exaggerated the degree of potential damage to the UK economy. We stress at this point that this is not a politicallydriven exercise. Most of the four-person team behind the research for this and our other papers voted 'Remain' in the 2016 referendum and would do so again if given the chance. Our purpose is rather to establish a sound basis for the ongoing debate on the likely potential economic impact of Brexit, and more generally to question the quality of economic analysis in dealing with major, macroeconomic policy issue like Brexit.

This is an edited extract from 'How the economics profession got it wrong on Brexit', Working Paper 493, Centre for Business Research, University of Cambridge, January 2018. It represents the views of the authors and not those of the Brexit blog, nor the LSE.

Ken Coutts is Assistant Director of Research at the Faculty of Economics, University of Cambridge.

Graham Gudgin is Honorary Research Associate at the Centre For Business Research (CBR) at Cambridge Judge Business School, University of Cambridge. He is also visiting Professor at the Ulster University and Chairman of the Advisory Board of the Ulster University Economic Policy Centre.

Jordan Buchanan is an Economist at the Economic Policy Centre at the Ulster University. 